\title{
Polineuropatia sensitiva reversível durante epidemia de arboviroses em Salvador, Bahia, Brasil
}

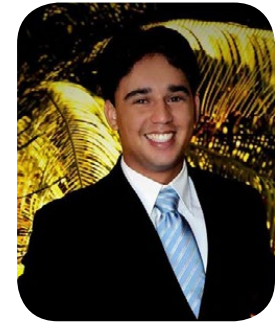

\author{
Mateus Santana do Rosário ${ }^{1}$
}

\section{RESUMO}

A síndrome de Guillan-Barré (SGB), uma polirradiculoneuropatia imunomediada, já foi descrita associada à infecção prévia por arbovírus, como os vírus da dengue (DENV), chikungunya (CHIK) ou zika (ZIKV). Neste artigo, foram descritos cinco casos de polineuropatia sensitiva reversível, na cidade de Salvador, durante o surto de arbovírus no Brasil em 2015. Todos os pacientes apresentaram predominantemente sintomas sensoriais: parestesias em "bota e luva" e hipoestesia. Portanto, foram relatados os casos de cinco pacientes com polineuropatia sensorial reversível, apresentando apenas alterações sensitivas e ausência de alterações em LCR ou em eletroneuromiografia.

Sorologias demonstraram que todos os pacientes tinham evidência prévia de infecção por arbovírus. Esta é a primeira descrição de dois casos com um subtipo específico de polineuropatia periférica com fortes evidências de infecção recente por CHIKV.

PALAVRAS-CHAVE: síndrome de Guillan-Barré; polineuropatia; arbovírus.

KEY-WORDS: Guillain-Barré syndrome; polyneuropathy; arbovirus.

\section{ARTIGO}

Síndrome de Guillain-Barré (SGB), uma polirradiculoneuropatia aguda, imunomediada, ocorre tipicamente em resposta a infecções virais e bacterianas. Associações entre esta síndrome e antecedentes de infecção por arbovírus, como a dengue (DENV), chikungunya (CHIKV) ou Zika vírus (ZIKV), foram relatadas em alguns estudos ${ }^{1,2}$.SGB manifesta-se geralmente como fraqueza generalizada e arreflexia, acompanhada por distúrbios sensoriais e autonômicos ${ }^{3}$. Síndromes neu- rológicas leves, associadas à infecção por ZIKV, foram previamente descritas, caracterizadas por distúrbios sensoriais isolados, de curta duração ${ }^{4,5}$.

Este artigo descreve uma série de casos de cinco pacientes internados em dois hospitais terciários, localizados na cidade de Salvador, durante o surto de 2015 do ZIKV, CHIKV e DENV no Brasil. O sangue e o líquido cefalorraquidiano (LCR) foram coletados no momento da admissão e testes sorológicos para arbovírus foram realizados para detectar anticorpos IgG e IgM anti-CHIKV, anti-DENV e anti-ZIKV. Exames de sangue adicionais foram realizados para descartar quaisquer causas alternativas de distúrbios musculares ou de nervos periféricos. Eletroneuromiografia (EMG) e estudos de condução nervosa foram realizados em dois pacientes.

Cinco pacientes apresentaram sintomas sensoriais predominantes: parestesia em padrão "bota e luva" (100\%) e hipoestesia (75\%). Não foram notadas anormalidades na marcha, nervos cranianos ou reflexos. A escalda funcional de Hughes (HFS) (graus: 0-6) foi usada para avaliar a gravidade da doença, com os maiores valores correspondentes ao maior grau de disfunção neurológica ${ }^{6}$. As manifestações neurológicas nestes pacientes foram consideradas leves $(100 \%$ tinham HFS <2). Todos os pacientes estudados relataram sintomas virais prévios ao surgimento de manifestações neurológicas. A duração média dos sintomas virais foi de 7,0 dias $( \pm 3,08)$ e a diferença média entre o início dos sintomas virais e os sintomas neurológicos à manifestação foi de 15,4 dias $( \pm 10,31)$. EMG não detectou anormalidades nos dois pacientes testados. O valor médio da proteína no LCR foi $26 \mathrm{mg} / \mathrm{dl}$ (RV $<40 \mathrm{mg} / \mathrm{dl}$ ).

Dois pacientes tiveram exame positivo para anticorpos anti-CHIKV IgM. Outros dois pacientes apresenta- 
ram positividade para anticorpos anti-ZIKV (um apenas $\lg G$ e outro $\lg M$ e $\lg G$ ). Os anticorpos anti-DENV IgG estavam presentes no soro de todos os pacientes. Nenhum paciente apresentou positividade para o anti-DENV IgM.

Vários casos de SGB e outras síndromes neurológicas relacionadas ao ZIKV e à CHIKV já foram relatados $^{7,8}$. No entanto, casos isolados de síndrome neurológica caracterizada por uma apresentação mais branda do que o SGB, que não atendiam aos critérios do SGB, devido à falta de critérios clínicos, anormalidades em EMG ou no LCR, foram previamente descritos em associação com a infecção pelo ZIKV, denominada polineurite transitória aguda (ATP) ou polineuropatia sensitiva reversível $(\mathrm{RSP})^{4,5}$.

No presente estudo, cinco pacientes se apresentaram com RSP, caracterizada como doença leve (HFS $<2$ ), apresentando distúrbio sensorial exclusivo e sem alterações nos estudos do LCR ou EMG.

Os resultados da sorologia demonstraram que todos os pacientes (100\%) apresentaram evidências de arboviroses anteriores, enquanto a maioria dos pacientes (80\%), infecção recente por ZIKV ou CHIKV. Neuropatia periférica relacionada ao CHIKV já havia sido descrita em relatos anteriores ${ }^{9}$. No entanto, descrito na literatura, este é o primeiro relato de dois casos descrevendo este subtipo específico de neuropatia periférica (RSP) com forte evidência de infecção recente por CHIKV.

A associação com ZIKV foi relatada anteriormente em séries de casos com achados clínicos semelhantes, levantando a suspeita de que estes possam ter sido um efeito neuropático ou inflamatório do ZIKV, caracterizado pela reversibilidade da inflamação e do inchaço dos nervos sensoriais ${ }^{4,5}$. Além de levantar a hipótese de que o ZIKV poderia infectar diretamente neurônios periféricos e promover morte celular ${ }^{10}$. Este relato deve servir como uma forma de chamar a atenção dos médicos e profissionais de saúde para a identificação de formas de doenças neurológicas possivelmente relacionadas a infecções por ZIKV e CHIKV.

\section{REFERÊNCIAS}

1. Verma R, Sahu R, Holla V. Neurological manifestations of dengue infection: a review. J Neurol Sci. 2014 Nov 15;346(1-2):26-34.

2. Pinheiro TJ, Guimarães LF, Silva MTT, Soares CN. Neurological manifestations of Chikungunya and Zika infections. Arq Neuropsiquiatr. 2016 Nov;74(11):937-43.

3. Wakerley BR, Uncini A, Yuki N, GBS Classifica- tion Group, GBS Classification Group. Guillain-Barré and Miller Fisher syndromes--new diagnostic classification. Nat Rev Neurol. 2014 Sep;10(9):537-44.

4. Medina MT, England JD, Lorenzana I, Medina-Montoya M, Alvarado D, De Bastos M, et. al.. Zika virus associated with sensory polyneuropathy. J Neurol Sci. 2016 Oct 15;369:271-2.

5. Nascimento OJM, Frontera JA, Amitrano DA, Bispo de Filippis AM, Da Silva IRF, RIO-GBS-ZIKV Research Group. Zika virus infection-associated acute transient polyneuritis. Neurology. 2017 Jun 13;88(24):2330-2.

6. Hughes RA, Newsom-Davis JM, Perkin GD, Pierce JM. Controlled trial prednisolone in acute polyneuropathy. Lancet Lond Engl. 1978 Oct 7;2(8093):750-3.

7. Acevedo N, Waggoner J, Rodriguez M, Rivera L, Landivar J, Pinsky B, et. al.. Zika Virus, Chikungunya Virus, and Dengue Virus in Cerebrospinal Fluid from Adults with Neurological Manifestations, Guayaquil, Ecuador. Front Microbiol. 2017;8:42.

8. Mehta R, Soares CN, Medialdea-Carrera R, Ellul M, da Silva MTT, Rosala-Hallas A, et. al.. The spectrum of neurological disease associated with Zika and chikungunya viruses in adults in Rio de Janeiro, Brazil: A case series. PLoS NegI Trop Dis. 2018;12(2):e0006212.

9. Chandak NH, Kashyap RS, Kabra D, Karandikar P, Saha SS, Morey SH, et. al.. Neurological complications of Chikungunya virus infection. Neurol India. 2009 Apr;57(2):177-80.

10. Oh Y, Zhang F, Wang Y, Lee EM, Choi IY, Lim $\mathrm{H}$, et. al.. Zika virus directly infects peripheral neurons and induces cell death. Nat Neurosci. 2017 Sep;20(9):1209-12.
1. Serviço de Neurologia Clínica do HSI
Endereço para correspondência:
drmateusan@gmail.com 